\title{
Nutrient cycling in the mycorrhizosphere
}

\author{
C. Azcón-Aguilar* and J.M. Barea \\ ${ }^{1}$ Departamento de Microbiología del Suelo y Sistemas Simbióticos, Estación Experimental del Zaidín, CSIC. \\ Prof. Albareda 1, 18008 Granada, Spain.*Corresponding author: conchi.azcon@eez.csic.es
}

\begin{abstract}
Optimizing the turnover and recycling of nutrients, a fundamental issue for the sustainability and productivity of agro-ecosystems is depending on the functionality of a framework of plant-soil interactions where microbial populations are involved. Both mutualistic symbionts and saprophytic microorganisms living at the root-soil interfaces, the rhizosphere, or in the plant-associated soil, are recognized as essential drivers of nutrient cycling, availability and capture. Among the mutualistic symbionts, arbuscular mycorrhizal (AM) fungi are one of the most influential groups of soil biota because after establishing the AM symbiosis with most plant species they enhance plant nutrient uptake properties. Saprophytic microorganisms are recognized for their abilities to propel nitrogen $(\mathrm{N})$ fixation and/or phosphorus (P) mobilization, two fundamental processes for sustain plant productivity. Mycorrhiza establishment changes the biological and physical-chemical properties of the rhizosphere, developing the socalled mycorrhizosphere. Particularly relevant is the mycorrhizosphere of legume plants since it also involves the symbiosis with $\mathrm{N}_{2}$-fixing nodulating rhizobial bacteria. In this overview of mycorrhizosphere interactions related to nutrient cycling, after describing the protagonist microorganisms, the mechanisms responsible for nutrient acquisition by AM-plants are first analyzed. Then, the processes involved in mycorrhizosphere establishment and functions are described. Finally, the achievements derived from managing selected AM fungi and beneficial bacteria interactions (mycorrhizosphere tailoring) are discussed. The use of ${ }^{15} \mathrm{~N}$ and ${ }^{32} \mathrm{P}$ to elucidate the contribution of the mycorrhizosphere components to plant nutrient acquisition is detailed.
\end{abstract}

Keywords: mycorrhizosphere services, plant nutrition, nutrient transport, isotope dilution techniques, mycorrhizosphere tailoring

\section{Introduction}

A sustainable productivity of either agricultural or natural soil-plant systems is necessary to guaranty future healthy food demands and environmental quality. To reach these aims is fundamental to promote plant performance and soil quality, properties which are the result of the interactions among chemical, physical and biological factors known as the "macro-components of soil fertility" 
(Altieri, 2004). A subset of the biological components of "soil fertility" is constituted by diverse genetic and functional groups of microorganisms known to participate in many processes responsible for a great array of agro-ecosystem services, including the biogeochemical cycling of plant nutrients.

Microbial activities are more relevant at the root-soil interfaces where microorganisms are attracted and promoted to grow, as stimulated by the abundance of available carbon substrates provided by the rhizodeposit pools. This results in establishing the so-called rhizosphere, a dynamic scenario of plantmicrobe interactions. The formation, development, significance, functioning and managing of the rhizosphere is a topic of current research interest, that has recently been reviewed (Barea et al., 2013a). An aspect to be considered is that the use of cultureindependent molecular approaches has evidenced that only about $1 \%$ of soil microorganisms, and $10 \%$ of those present in rhizosphere microhabitats, are able to grow in standard culture media and can therefore be isolated and multiplied (Hirsch et al., 2013). While the activities of culturable microorganisms have been, and are being, the subject of many studies concerning nutrient cycling, those of unculturable microorganisms are only recently being investigated, usually by combining molecular microbial ecology techniques with ecophysiology and plant genetics approaches (Zancarini et al., 2013). Current studies are evidencing that non-culturable microbes are also involved in activities related to plant growth, by propeling nutrient cycling and stress alleviation, playing a beneficial role in nutrient deficient soils (Zolla et al., 2013).

Diverse types of microorganisms from the subset of those culturable are involved in rhizosphere interactions, however most studies focus on bacteria and fungi. These microorganisms establish either saprophytic or symbiotic relationships with the plant, where the symbiont habit could be either parasitic or mutualistic. Among the beneficial saprophytic rhizosphere microbes certain bacteria, namely the so-called plant growth promoting rhizobacteria (PGPR), and fungi, like the pathogen antagonist Trichoderma spp., have received much research attention (Lugtenberg, 2015). Particularly, the PGPR are involved in several plant-beneficial activities such as nutrient cycling, including nitrogen $(\mathrm{N})$ fixation and phosphate $(\mathrm{P})$ mobilization, and in the biological control of plant pathogens (Martínez-Viveros et al., 2010). The $\mathrm{N}_{2}$-fixing rhizobial bacteria (Willems, 2007; Dos Santos et al., 2012) and the multifunctional arbuscular mycorrhizal (AM) fungi (Schüßler and Walker, 2011) are the most relevant representatives of beneficial plant symbionts related to nutrient cycling. Mycorrhizal fungi include about 50000 fungal species that form mycorrhizal associations with about 250 000 plant species. These fungi are known to play fundamental roles in terrestrial ecosystems acting as drivers of nutrient and carbon cycles. It is accepted that up to $80 \%$ of plant $\mathrm{N}$ and $\mathrm{P}$ can be provided by mycorrhizal fungi (van der Heijden et al., 2015). The AM fungi, in particular, establish the most widespread mycorrhizal type (arbuscular) with approximately 80 $\%$ of terrestrial plants. They carry out diverse activities benefiting plant fitness and soil quality, including an enhanced nutrient supply and plant health promotion. Root colonization by AM fungi changes several plant physiological traits, particularly those affecting root exudation patterns. This, in turn, alters the biological and chemical properties of the rhizosphere. Indeed, the extraradical AM mycelium itself represents a biological and physical novelty in the soil outside the rhizosphere. Consequently, the establishment of the AM symbiosis affects the structure and diversity of microbial communities not only in the rhizosphere but also in other soil microhabitats beyond the rhizosphere. This gives way to a new scenario for the root-associated 
microbiome, the so-called mycorrhizosphere, were multiple microbial interactions occur. Moreover, interactions involving selected $\mathrm{AM}$ fungi, $\mathrm{N}_{2}$-fixing rhizobial bacteria and other beneficial saprophytic microorganisms can be managed (mycorrhizosphere tailoring) resulting in a feasible biotechnological tool for improving sustainable plant performance, healthy food production and soil quality (Barea et al., 2013a; Courty et al., 2015).

In the context of mycorrhizosphere tailoring, diverse co-inoculation studies based on applying selected AM fungi and other plant growth promoting microorganisms have been carried out. In a recent review on mycorrhizosphere management (Barea et al., 2013b), most of the studies revisited rely on interactions related to either stress alleviation or ecosystem restoration, and include: (a) biological control of root pathogens; (b) phytoremediation of heavy metal contaminated soils; (c) alleviation of the negative impact of osmotic stressors (drought, salinity...); (d) improvement of soil quality; and (e) restoration of degraded ecosystems/threatened flora. However, in such a review article mycorrhizosphere interactions related to nutrient cycling were not considered. Therefore, and because these interactions are fundamental for agro-ecosystem sustainability and productivity, current information on mycorrhizosphere developments involving nutrient cycling deserve a comprehensive analysis. Actually, this is the main objective of this article, focused on two major nutrients, namely $\mathrm{N}$ and $\mathrm{P}$, fundamental because they usually limit plant growth. To approach this general objective, the role of root-associated culturable microorganisms actually involved in nutrient cycling are first described. Then, the information on AM establishment and function, and the mechanisms responsible for nutrient acquisition by AM-plants are analysed. Subsequently, the processes related with mycorrhizosphere formation are summarized, with a special emphasis to the mycorrhizosphere of legumes since it also involves the interaction with $\mathrm{N}_{2}$-fixing nodulating bacteria, a relevant scenario of plantmicrobiome interactions related to nutrient cycling. Finally, the practical agro-ecological benefits derived from mycorrhizosphere tailoring are considered.

\section{Root-associated microorganisms involved in plant nutrient cycling}

As previously stated, research on microorganisms involved in $\mathrm{N}$ or $\mathrm{P}$ cycling is mainly centered on $\mathrm{N}_{2}{ }^{-}$ fixers, P-mobilizers and AM fungi.

\section{1. $N_{2}$-fixing bacteria}

In spite of molecular nitrogen $\left(\mathrm{N}_{2}\right)$ is an unlimited resource accounting for $78 \%$ of the atmospheric gases (Elser et al., 2007), agricultural productivity is frequently limited by the availability of $\mathrm{N}$. This is because plants are not able to use $\mathrm{N}_{2}$. Therefore this source of $\mathrm{N}$ must be first chemically or biologically reduced $\left(\mathrm{N}_{2}\right.$-fixation) into a plant-accessible form (ammonia).

The ability of microorganisms to reduce atmospheric $\mathrm{N}_{2}$ to ammonia is restricted to a subset of prokaryotes (bacteria and archaea), the sole organisms which possess the enzyme nitrogenase, exclusive responsible for such activity (Olivares et al., 2013; de Bruijn, 2015). Recent studies demonstrate that the presence of nitrogenase-like sequences in microbial genomes is much more extended than preliminary observations indicated (Dos Santos et al., 2012).

The most studied groups of $\mathrm{N}_{2}$-fixers involve freeliving, associative and symbiotic bacteria (Olivares et al., 2013). Free-living bacteria from diverse genera have been reported to be able to fix $\mathrm{N}_{2}$ that these microbes use as a source of $\mathrm{N}$ for themselves, with low direct $\mathrm{N}$ transfer to the plant. This sub-set of $\mathrm{N}$-fixers 
has a limited agronomic significance. However, other bacteria able to establish mutualistic symbioses (root nodules) with the plant are able to transfer the fixationderived ammonium to plants. Actually, bacteria belonging to diverse genera, collectively termed as "rhizobia", can fix $\mathrm{N}_{2}$ in mutualistic symbiosis with legume plants, while others (actinomycetes), belonging to the genus Frankia, forms $\mathrm{N}_{2}$-fixing nodules on the root of the so-called "actinorrhizal" plant species. The so-called associative bacteria colonize root surfaces and can even invade intercellular tissues; however, specialized $\mathrm{N}_{2}$-fixing structures are not formed (Olivares et al., 013). Other bacteria form diazotrophic rhizocenosis, like Azospirillum, which are free-living $\mathrm{N}_{2}$-fixing rhizobacteria but live most closely associated to plant roots than the rest of freeliving bacteria. Azospirillum enhance N supply to the plant but act mainly by increasing the ability of the root system for $\mathrm{N}$ uptake from soil rather than as $\mathrm{N}_{2}-$ fixing bacteria (Dobbelaere et al., 2001). The rhizobialegume symbiosis is considered as the most important and probably more efficient $\mathrm{N}_{2}$-fixing system by far.

\subsection{Phosphate mobilising microorganisms}

$\mathrm{P}$ availability is the most limiting factor for crop yield in many arable soils all over the world. Therefore, the capacity of some microorganisms to mobilize $\mathrm{P}$ from poorly available sources of this nutrient can help plant P nutrition (Barea and Richardson, 2015). In this section we focus on mechanisms whereby microbial activities result in an increased release of available $P$ from sparingly available soil $\mathrm{P}$ forms, either inorganic (solubilisation) or organic (mineralisation).

\subsection{Phosphate solubilisation}

Bacteria and fungi isolated from soil are able to solubilise in vitro inorganic phosphate sources, which are insoluble under the form of calcium, aluminium or iron salts. Diverse genera possess species able to solubilise phosphates, including bacteria, such as Bacillus, Enterobacter, Rhizobium, Bradyrhizobium, Panthoea, Erwinia, and Pseudomonas, and fungi, like Aspergillus, Trichoderma and Penicillium (Marschner, 2008). In the case with sparingly soluble calcium phosphates, the mechanisms of solubilisation are mainly based on the release of proton and acidification of the medium, but chelation processes are also involved. For iron or aluminium phosphates, solubilisation is based on the production of chelating organic acids. Actually, effective chelation processes result in the sequestration of calcium, iron or aluminium, with the subsequent release of $\mathrm{P}$ to soil solution. Chelating organic acids, from microbial $\mathrm{C}$ metabolism, include citrate, oxalate, lactate, succinate, gluconate and 2-ketogluconate. Siderophore production has also been reported to be involved in the solubilisation of Fe phosphates (Marschner, 2008).

\subsection{Phosphate mineralisation}

Bacteria and fungi isolated from soil are able to hydrolyse organic $\mathrm{P}$ substrates, a process termed mineralisation of organic $\mathrm{P}$ which results in the release of orthophosphate to the soil solution (Richardson et al., 2009). Species of both bacteria (mainly Bacillus and Pseudomonas) and fungi (mainly Aspergillus and Penicillium) are commonly described as P mineralising microorganisms (Marschner, 2008). Mineralisation of organic $\mathrm{P}$ is actually a solubilisation/hydrolytic process accomplished through the activity of phosphatase enzymes. Mineralising microorganisms produce diverse types of enzymes either non-specific, as the acid and alkaline phosphatases, or specific, as phytases, known to release orthophosphate from phytate and other inositol phosphates (Jorquera et al., 2008). 


\subsection{Significance of phosphate mobilising microorganisms in improving plant nutrition}

While it is clear that soil microorganisms are key responsible for the functioning of the soil $\mathrm{P}$ cycle, the extent to which the $\mathrm{P}$ released by the activities of soil microorganisms actually benefits plant $\mathrm{P}$ nutrition deserves further research (Antoun, 2012). Inoculation with $\mathrm{P}$ mobilising microorganisms has been demonstrated to increase, in some cases, the availability of orthophosphate, leaving the nutrient ready to be taken up by the plant (Richardson et al., 2009). However, a generalisation of the effectiveness of $\mathrm{P}$ mobilising microorganisms in soil is doubtful. There are actually some inherent difficulties. First of all, C limitation in non-rhizosphere microhabitats may preclude orthophosphate release from sparingly available $\mathrm{P}$ sources by microbiologically-driven activities (Whitelaw, 2000). While this is true for the bulk soil, orthophosphate release can take place in discrete microhabitats in the target soil. Other difficulties arise from the translocation of the released orthophosphate ions from non-rhizosphere microhabitats to root uptake zones because they are usually re-fixed by soil components while diffusing slowly towards the root surface. In the case of phytases their effectiveness in many soils remains unclear since these enzymes lost activity when adsorbed to soil particles. Moreover, inositol phosphates can be adsorbed or precipitated with iron or aluminium oxides and other soils constituents affecting their availability to phytases (Marschner, 2008). Indeed, mobilised orthophosphate can be quickly immobilized by microbial biomass, and it is unclear whether this $\mathrm{P}$ can be made immediately available to plants (Richardson, 2007). The highly transient status of orthophosphate in nature has therefore implications for its efficacy in promoting plant growth. However, if an effective mycorrhizal mycelium reaches microhabitats where orthophosphate is made available by $\mathrm{P}$ mobilising microorganisms, the nutrient can be taken up and transferred to plant roots (Richardson et al., 2009).

To date much of the work on $\mathrm{P}$ mobilization involves soil microorganisms that have been isolated and grown in culture media. The non-culturable populations likely include microorganisms involved in $\mathrm{P}$ mobilisation and must be taken into account with regard to plant nutrition (Barret et al., 2013). This is particularly relevant considering that plants can play a fundamental role in shaping microbial communities in their rhizospheres. Thus several approaches are being followed to ascertain whether the root-soil microbiome could be biased to improve orthophosphate availability (Browne et al., 2013).

\subsection{Arbuscular mycorrhizal (AM) fungi}

AM fungi are ubiquitous soil-borne fungi whose origin and divergence have been dated back over 500 million years (Bonfante and Genre, 2008; Honrubia, 2009; Schüßler and Walker, 2011; Barea and AzcónAguilar, 2013). They are included into a monophyletic phylum in the true Fungi, the Glomeromycota (Schüßler et al., 2001).

The most relevant biological characteristic of AM fungi is their capacity to form AM associations with members of all phyla of land plants regardless their geographical distribution, since they have been found in almost all terrestrial agro-ecosystems worldwide and in all soil types and biomes (Brundrett, 2009). Morphological and phylogenetic (molecular) studies suggest that AM fungi played a key role in land colonization by plants, and that primitive roots coevolved in association with AM fungi and have perpetuated associated in the extant AM root systems present in almost all vascular plants (Brundrett, 2002). Among other important characteristics, AM fungi are unculturable and therefore obligate biotrophs (Schüßler 
and Walker, 2011; Barea and Azcón-Aguilar, 2013). The character of obligate symbionts means that they cannot complete their life cycle without colonizing a host plant, a fact that has hampered the study of their biology and biotechnological applications. As demonstrated by diversity analyses based on molecular approaches, AM fungi exhibit little host specificity and a single plant can be colonized by many different AM fungi. However, a certain degree of host preference (functional compatibility) has been evidenced, a fact relevant to understand the importance of AM fungal diversity in maintaining the diversity, stability and productivity of natural ecosystems and the effectiveness of AM symbioses in plant production (Barea and Azcón-Aguilar, 2013).

\section{Establishment and functioning of arbuscular mycorrhiza}

\subsection{General concepts}

As indicated before, most vascular plant species on Earth are able to form the universally distributed mycorrhizal associations, becoming a fundamental component of plant life in both natural and agricultural systems (Smith and Read, 2008; Brundrett, 2009; van der Heijden et al., 2015). Diverse mycorrhizal types are recognized according to the plant and fungal taxa involved, but the AM symbiosis is the most common type. It is formed by about $80 \%$ of terrestrial plant species, including almost all species of agronomic interest and many shrub and tree species from natural ecosystems (Smith and Read, 2008; Brundrett, 2009). According to well-accepted findings we can conclude that the AM symbiosis is vital for plant nutrition and contributes to a sustainable crop production (Jeffries et al., 2003; Barea, 2010; Borie et al., 2010; Gianinazzi et al., 2010; Mundstock et al., 2010; Jeffries and Barea, 2012). Indeed, the AM symbiosis is essential for the continued cycling of nutrients within the plant community, being fundamental to avoid nutrient sequestration or leaching.

The first demonstrated effect of AM symbioses was their beneficial role in plant nutrition (Koide and Mosse, 2004), an activity which fit well with the aims of this chapter. In this section we summarize the processes involved in AM formation and functioning and its consequences on nutrient uptake from soil.

\subsection{Arbuscular mycorrhiza establishment}

The cellular and developmental programmes modulating the events occurring from AM propagule activation until the intracellular accommodation of the fungal symbiont and the formation of functional arbuscules, have recently been reviewed (Gutjahr and Parniske, 2013; Bonfante and Desirò, 2015). Hyphae from germinated spores develop poorly in the soil in the absence of a host plant (the asymbiotic mycelium). However, when hyphae perceive host plant exudates start to branch profusely, thus improving their chance to contact the root surface. This molecular crosstalk prior to physical contact constitutes the so-called pre-symbiotic stage, and it is due to the recognition by the fungus of plant signaling molecules, the strigolactones, which stimulate the fungus to ramify (López-Ráez et al., 2011). In the other direction, plants perceive diffusible signals, called "Myc factors" (lipo chitooligosaccharides), produced by the fungus being able to induce symbiosis-specific responses in the host root (Parniske, 2008; Genre and Bonfante, 2010; Maillet et al., 2011).

After contacting the root epidermal cells the fungal hyphae develops an appressorium from which the fungus penetrates the epidermal cells and then the colonization proceeds to develop an intraradical mycelium (IRM). Characteristically, root colonization continues until the formation of the tree- 
shaped structures, the arbuscules, through repeated dichotomous branching within the root cortical cells. Each fungal branch within a plant cell is surrounded by a plant-derived periarbuscular membrane which separates physically the fungus from the cell cytoplasm. This apoplastic interface between the fungal plasma membrane and the plant periarbuscular membrane plays a fundamental role in the exchange of symbiotic signals and in the bidirectional transfer of nutrients between symbionts (Gutjahr and Parniske, 2013; Bonfante and Desirò, 2015).

During root colonization the fungus also grows in the soil surrounding the root to establish a mycelial network, which is called the extraradical mycelium (ERM). Spores develop in the ERM, in many cases associated to "branching absorbing structures", where they develop until maturity, accomplishing thereby the fungal life cycle (Bago et al., 1998). The ERM is a tri-dimensional structure specialized in the uptake of mineral nutrients from the soil solution, having a special incidence on those nutrients diffusing slowly or that are present in low concentrations, as it is the case with phosphate and ammonia. The ERM is able to absorb and transport nutrients at a distance up to 25 $\mathrm{cm}$ (Jansa et al., 2003). Hyphal length densities in field soils range from 3 to $14 \mathrm{~m} / \mathrm{g}$ according to the fungal ecotype involved and the functional compatibility degree with the host (Smith and Smith, 2012).

\subsection{Arbuscular mycorrhiza functioning}

Because of their character of obligate symbionts, AM fungi depend on their host plant to obtain the $\mathrm{C}$ compounds they need for growth and metabolism, in exchange for mineral nutrients (mainly $\mathrm{P}$ ), that the ERM takes up from the soil solution and transports to the root. A reciprocal reward is needed to stabilize the cooperation between both AM symbiotic partners (Kiers et al., 2011). The continuity ERM-IRM is fundamental for the distribution and movement of nutrients within the plant-soil environment (Richardson et al., 2009).

\subsection{Nutrient uptake from soil by the AM symbiosis}

The use of ${ }^{32} \mathrm{P}$-based isotope dilution approaches, as discussed later in this chapter, has allowed us to corroborate and quantify the AM fungal contribution to plant $\mathrm{P}$ nutrition. AM fungi take up $\mathrm{P}$ from the same pool of soluble ions than roots, therefore the AM mycelium can be considered as an extension of the root system. The isotopic techniques showed that most of the P taken up by mycorrhizal plants was via the fungal partner (Smith and Smith, 2012). Some studies indicate that phosphatase activity is higher in soil associated to AM-colonized roots, what suggests the possibility that the AM fungus can access alternative $P$ sources in soil via these enzymatic activities. However, there is no clear evidence that this fungalmediated activity has any agronomic influence (Barea and Richardson, 2015).

Several studies have demonstrated that AM fungi can also contribute to plant $\mathrm{N}$ nutrition by taken up this nutrient from soil (Barea et al., 2005; Veresoglou et al., 2012). To ascertain and quantify such a contribution techniques based on the use of the ${ }^{15} \mathrm{~N}$ isotope were followed, as expanded later. Plants, either mycorrhizal or not, were grown in soil added with labelled $\mathrm{N}$ sources, ammonium or nitrate (Tobar et al., 1994a; b; Mäder et al., 2000). The main conclusions are that the AM symbiosis enhances the uptake of ammonium in all conditions and also nitrate in drought stress situations (Tobar et al., 1994a; b). Moreover, it was investigated whether the AM mycelium had access to $\mathrm{N}$ sources not available for non-mycorrhizal plants. The approach was to measure the apparent plant available $\mathrm{N}$ pool size, i.e. the $\mathrm{A}_{\mathrm{N}}$ value of the soil, where grown either AM or non-mycorrhizal plants. 
This technique, described later in this chapter, allowed to demostrate that the $\mathrm{A}_{\mathrm{N}}$ value of the soil associated to AM-plants was higher than of the soil associated to non-mycorrhizal controls, supporting that the AM mycelium is accessing $\mathrm{N}$ forms sparingly available for non-AM plants.

In addition to $\mathrm{P}$ and $\mathrm{N}$, AM fungi are able to improve the uptake of other nutrients, such as $\mathrm{K}, \mathrm{Ca}, \mathrm{Zn}, \mathrm{Cu}$ or Fe (Liu et al., 2000). As in the case with $\mathrm{P}$ and N, the ability of AM fungi to take up these nutrients from the soil solution is attributed to the capability of the ERM to exploit more efficiently large volumes of soil, and to the presence of nutrient transporters specific of the AM symbiosis (Gianinazzi-Pearson et al., 2012).

\subsection{Molecular basis of nutrient exchange ( $P, N$ and C) in the AM symbiosis}

The biochemical and molecular mechanisms involved in the coordinated bidirectional nutrient exchange between AM symbionts have been recently reviewed, paying special attention to the characteristics, function and regulation of the transportome genes (Smith and Smith, 2011; Franken et al., 2012; Gianinazzi-Pearson et al., 2012; Harrison, 2012; Haage and Parniske, 2013; Bonfante and Desirò, 2015).

In summary, and with regard to the phosphate transport processes, high affinity transporters involved in inorganic phosphate $(\mathrm{Pi})$ uptake from soil by AM fungi have been identified in the fungal ERM (Harrison and van Buuren, 1995; Maldonado-Mendoza et al., 2001; Benedetto et al., 2005). Once Pi has been taken up by the fungus is incorporated into the fungal vacuoles where it is accumulated as polyphosphate (polyP) (Kikuchi et al., 2014). Phosphate, as polyP chains, is transferred to the arbuscules where it is released from the fungus and transported across the periarbuscular membrane into the root cortical cell. Gene expression studies of plant Pi transporters have shown that the
AM symbiosis strongly induces, sometimes de novo, the expression of the so-called mycorrhiza-induced/ specific Pi transporters (Karandashov and Bucher, 2005). These are located in the periarbuscular membrane and have been identified in several plant species (Harrison et al., 2002; Tamura et al., 2012; Xie et al., 2013). Indeed, these genes are considered as functional markers for the AM symbiosis (Harrison, 2012). Consequently, mycorrhizal plants are capable of absorbing $\mathrm{P}$ both directly through root epidermis (direct pathway), and via the AM fungus (mycorrhizal pathway) that delivers $\mathrm{P}$ to the root cortex (Smith and Smith, 2011). A loss-of-function mutation in a mycorrhiza-specific Pi transporter gene was found to correlate with a reduction of shoot biomass and cob production in maize growing in a P-limited soil under field conditions (Willmann et al., 2013). Besides, the uptake of ${ }^{33} \mathrm{P}$-labeled orthophosphate via the mycorrhizal pathway was strongly impaired in colonized mutant plants.

As in the case of $\mathrm{P}$, both pathways (direct and mycorrhizal) could act for $\mathrm{N}$ uptake from the soil. Inorganic $\mathrm{N}$ can be taken up by the ERM, either as $\mathrm{NH}_{4}^{+}$or $\mathrm{NO}_{3}^{-}$. The absorbed $\mathrm{N}$ is assimilated into arginine in the fungal cytoplasm and then transferred, associated with polyP via vacuoles, to the IRM where it is released as ammonium to the plant (Govindarajulu et al., 2005). Genes encoding ammonium transporters have been identified in AM fungi (López-Pedrosa et al., 2006; Pérez-Tienda et al., 2011), as well as plant ammonium transporters specific to or induced by the symbiosis and located in the periarbuscular membrane (Gomez et al., 2009; Guether et al., 2009; Kobae et al., 2010; Koegel et al., 2013; Perez-Tienda et al., 2014). It has been proposed that this mycorrhizal $\mathrm{N}$ uptake pathway is similar to the mycorrhizal Pi uptake pathway. However, much less is known about the contribution of the $\mathrm{N}$ supplied by AM fungi on plant $\mathrm{N}$ assimilation. 
The mechanisms involved in $\mathrm{C}$ transfer from the plant to the fungus are still poorly defined. It is well accepted that mycorrhizal plants direct up to $20 \%$ more photosynthate to the root system than non-mycorrhizal plants (Willis et al., 2013). However, this is not detrimental for the plant because usually the rate of photosynthesis increases substantially more than the $\mathrm{C}$ costs of the $\mathrm{AM}$ symbiosis (Kaschuk et al., 2009). In the mycorrhizal plant, sucrose, the form in which photosynthetically fixed carbon is translocated to the plant sink organs, is delivered into the apoplast at the arbuscular interfaces. Then it is hydrolyzed by cell wall invertases to hexoses which are taken up by fungus (Bago et al., 2002; Ferrol and Pérez-Tienda, 2009). Up to now, only a high affinity monosaccharide transporter has been reported in an AM fungus (Helber et al., 2011).

Some models that schematically illustrate the integration of the mechanisms involved in the coordinated nutrient exchange ( $\mathrm{P}, \mathrm{N}$ and $\mathrm{C})$ between plant and fungus in the AM symbiosis have been proposed (Ferrol and Pérez-Tienda, 2009; Bonfante and Genre, 2010; Haage and Parniske, 2013).

\subsection{Mycorrhizal effects on plant physiology}

The most evident effect of AM formation is the stimulation of plant growth together with an improved mineral nutrition. However, the establishment of the AM symbiosis implies remarkable changes in the physiology of the host plant. The changes span from alterations in the hormonal balance to altered primary and secondary metabolism. Some of these changes are related to the improvement of mineral nutrition, while others no. The metabolic changes not only occur at the root level, but also in other plant parts, such as shoot, leaves and fruits. As an example, it is well known the positive control on photosynthesis of P supplied by the AM symbiosis, i.e. the C-P balanced trade between the symbionts (Smith and Smith, 2012).
The global reprogramming of plant functions in mycorrhizal plants has an impact on their interactions with the environment, modifying their responses to stresses and their interactions with below- and above-ground organisms. Phytohormones, as signal molecules, have been found to be involved in the control of the AM symbiosis developments. In turn, AM establishment regulate hormone homeostasis in the plant and its response to environmental cues, enabling plants to flexibly respond and adapt their phenotype to challenging situations by regulating diverse processes, for example photosynthesis and $\mathrm{P}$ allocation (Pozo et al., 2015).

\section{Interactions between mycorrhizal fungi and other rhizosphere microorganism: the mycorrhizosphere}

As previously indicated, AM fungal colonization affects the structure and diversity of the rhizosphere microbial communities giving way to the so-called mycorrhizosphere. Mycorrhizal inoculation improves the establishment of both inoculated and indigenous bacteria, which in turn enhance AM colonization (Toljander et al., 2007). Microbial interactions in the rhizosphere/mycorrhizosphere are summarized here.

\subsection{Reciprocal aids in plant-associated microbiome: bacteria at helping AM establishment and changing a rhizosphere into a mycorrhizosphere}

Some rhizosphere bacteria are known to facilitate mycorrhiza formation and the term "mycorrhizahelper-bacteria" (MHB) was coined to refer to these bacteria (Frey-Klett et al., 2007). MHB produce compounds or create conditions that increase spore germination rate and/or stimulate AM fungal mycelia in the rhizosphere. The production of plant hormones by soil microorganisms has been suggested as mediating these processes (Pivato et al., 2009; Larsen et al., 2009). 
As mentioned above, root colonization by AM fungi changes many aspects of plant physiology, including mineral nutrient composition of plant tissues, plant hormonal balance and $\mathrm{C}$ allocation patterns. These changes alter the chemical composition of root exudates and, consequently, affect both quantitatively and qualitatively microbial populations in the rhizosphere. Thereby, the rhizosphere results in a new environment, the mycorrhizosphere (Barea et al., 2013a). Alternative terminologies were also proposed, as mycosphere or hyphosphere, in reference to the environment created by the presence of the AM mycelium outside the rhizosphere, since the fungus supplies $\mathrm{C}$ sources and introduces a new physical environment for the soil microbial populations. However, generically, the term mycorrhizosphere is usually used to refer to the rhizosphere of a mycorrhizal plant (Finlay, 2008).

\subsection{Mycorrhizosphere interactions for improving plant $P$ acquisition}

Since the pioneering experiments by Azcón et al. (1976), several studies have shown that mycorrhizosphere interactions involving P mobilising microorganisms are relevant to the cycling of $\mathrm{P}$ and its absorption by the plant (Barea et al., 2002; Zaidi and Khan, 2007; Zhang et al., 2014). The bases of these interactions rely on three key facts (Barea et al., 2005):

(i) The external mycelium of AM fungi acts as a bridge between roots and the surrounding soil microhabitats giving access to $\mathrm{Pi}$ from the soil solution beyond the Pi-depletion zone surrounding roots.

(ii) Microorganism-driven activities can release $\mathrm{Pi}$ ions from sparingly available $P$ sources, but these ions may be subject to further reactions in soil, for example through either 're-fixation' into soil components or immobilisation into microbial biomass. (iii) If the $\mathrm{Pi}$ made available by $\mathrm{P}$ mobilising microorganisms in discrete soil microhabitats can be taken up more efficiently by an AM mycelium, then the resulting microbial interaction would by acting synergistically to improve P supply to the host plant. These interactions are further expanded in this chapter when describing experiments based on the use of isotopic, ${ }^{32} \mathrm{P}$-based, approaches.

\subsection{The tripartite symbiosis in legumes}

The coexistence of endophytic bacteria and fungi inhabiting the root system of legume plants was first described by Janse (1896), and some years later the root-fungal association was recognized as a "mycorrhizal" symbiosis (Jones, 1924). Asai (1944) was the first to suggest that root nodulation by rhizobial bacteria was dependent on mycorrhizal colonization. From these pioneering studies, the high mycotrophic level of legume plants and the effect of AM fungi at improving nodulation and $\mathrm{N}_{2}$ fixation were described in different situations (see Azcón and Barea, 2010 for references). Actually, rhizobia, AM fungi and the legume host interact both at the colonization level and symbiotic functioning. Interestingly, legume nodulation and arbuscular mycorrhization (and even some plant-parasitic interactions) share some common similarities in the recognition and signalling models, as evidenced by using "omic" technologies (Parniske, 2008; Genre and Bonfante, 2010; Jayaraman et al., 2012).

Many studies have analysed the physiological and biochemical basis of AM fungi, rhizobia and legume interactions and these have recently been reviewed (Azcón and Barea, 2010). The information recorded in this review article pointed out that the main reason for the beneficial effect of AM fungi on nodule formation and functioning is the supply of $\mathrm{P}$ to satisfy the high $\mathrm{P}$ demand of 
the processes involved in $\mathrm{N}_{2}$-fixation, leading to an increased fixation rates.

Clearly, mycorrhizosphere interactions in legume plants have a relevant significance on $\mathrm{N}$ and $\mathrm{P}$ cycling in the biosphere to benefit sustainable agriculture, involving legume crops, and to improve the productivity of natural ecosystems where legumes are key components of the plant communities (Courty et al., 2015).

\section{Mycorrhizosphere tailoring}

Managing mycorrhizosphere interactions (mycorrhizosphere tailoring), involving coinoculation with selected AM fungi and other beneficial microorganisms, is recognized as a feasible biotechnological tool to improve plant growth and health, and soil quality (Barea et al., 2013a). Particularly relevant for the aims of this chapter are those interactions related to nutrient cycling where several microbial consortia have been assayed.

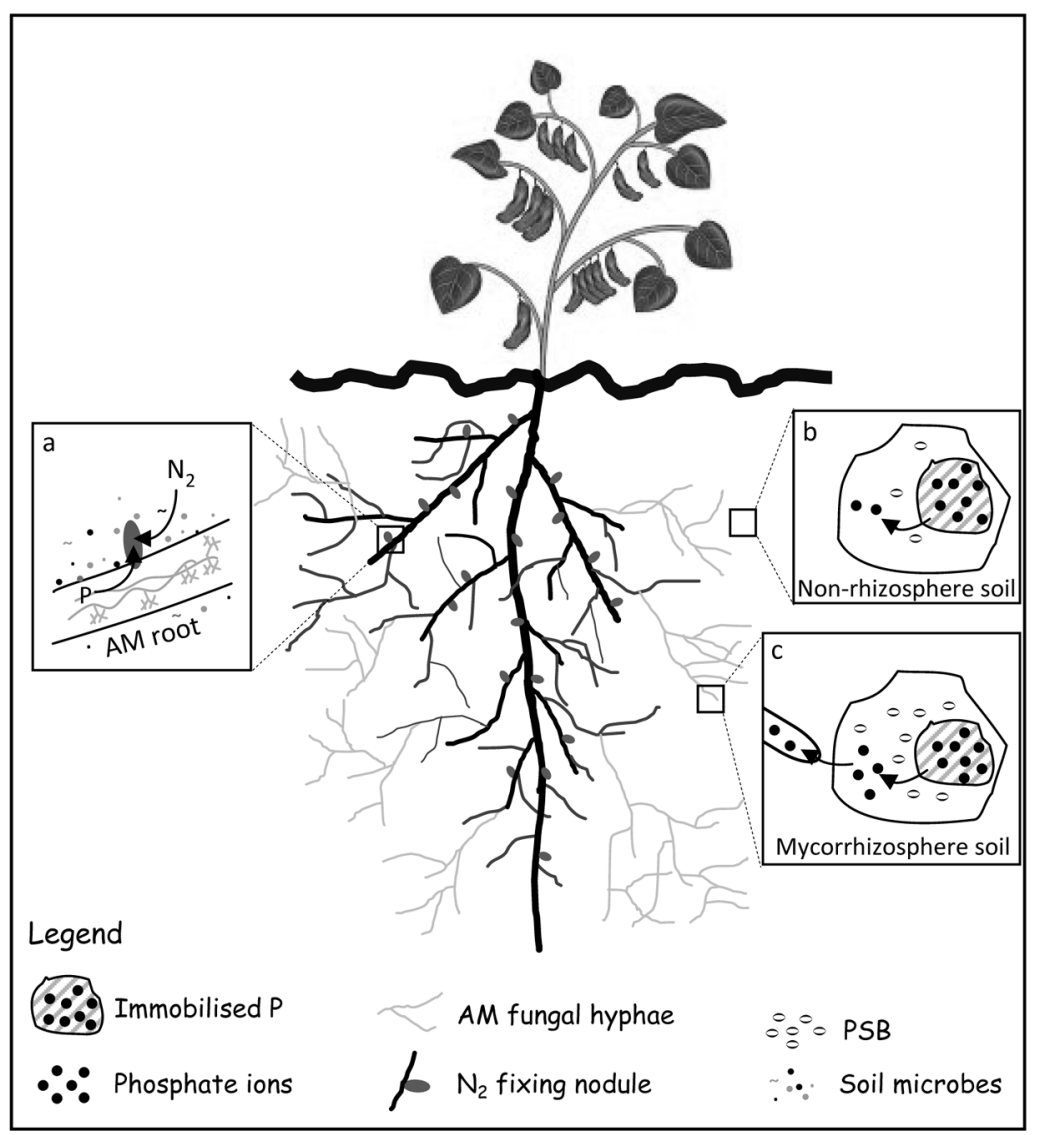

Figure 1. Interactions in the mycorrhizosphere involving arbuscular mycorrhizal (AM) fungi, phosphate mobilising bacteria (PSB) and rhizobia to benefit plant nutrition: (a) AM fungi provide $\mathrm{P}$ for the high energy-demanding process of $\mathrm{N}_{2}$-fixation; (b) limited plant access to the Pi mobilised by PSB in non-rhizosphere soil; (c) AM fungal uptake and transport of the Pi mobilised by PSB in the mycorrhizosphere. 


\subsection{Target microbial consortia}

Most of the mycorrhizosphere tailoring studies so far reported in relation to $\mathrm{N}$ and/or $\mathrm{P}$ acquisition by the common host AM-plant involve $\mathrm{N}_{2}$-fixing nodulating rhizobia and/or phosphate mobilising bacteria (Barea et al., 2005; Azcón and Barea, 2010). As P mineralization is in fact a "solubilisation" process we are using hereafter the term "phosphate solubilising bacteria" to maintain the acronym "PSB", which is that used in the publications discussed in this section. Figure 1 illustrates on these interactions.

In addition, co-inoculation studies involving AM fungi and Azospirillum spp. have also been reported (Barea et al., 2005, 2013a). These bacteria appear to act mainly by changing the morphology, geometry and physiology of the root system through plant hormone production, resulting in an enhanced ability of the roots for $\mathrm{N}$ capture from the soil solution (Dobbelaere et al. 2001; Hartman and Bashan, 2009; GutierrezMañero and Ramos-Solano, 2010). Some studies showed that Azospirillum enhance AM colonization and the plant response and that, conversely, AM fungi favored Azospirillum establishment. An improvement of biomass and $\mathrm{N}$ accumulation in dually inoculated plants was usually found (Vázquez et al., 2000; Russo et al., 2005; Miyauchi et al., 2008).

Selected studies on mycorrhizosphere biotechnology derived from co-inoculation of AM fungi, rhizobia and/ or PSB concerning N and P cycling are described here, giving a special emphasis to studies reporting research approaches based on the use of isotope dilution techniques. Thus, these methodologies are summarized first.

\subsection{Isotope-aided approaches to assess} mycorrhizosphere effects on plant nutrition

The application of isotopic ${ }^{32} \mathrm{P}$ - and ${ }^{15} \mathrm{~N}$-dilution techniques has been decisive for evaluating the impact of agronomic managements on $\mathrm{N}$ and $\mathrm{P}$ cycling and plant nutrition (Danso, 1986; Zapata, 1990; Fardeau, 1993; Zapata and Axmann, 1995). Accordingly, these isotope-based methodologies have been further used to ascertain the individual or interactive effects of $\mathrm{PSB}$, AM fungi and $\mathrm{N}_{2}$-fixers on $\mathrm{N}$ or $\mathrm{P}$ supply to the plant in a managed mycorrhizosphere (Barea et al., 2005; Azcón and Barea, 2010). First of all, some brief conceptual approaches which will help understanding the fundamentals of the isotope-aided techniques are given to illustrate non-specialist readers.

\subsection{Fundamental concepts}

Concerning application of ${ }^{15} \mathrm{~N}$-aided methodologies, the basic ideas, which were established many years ago (Danso, 1986; Zapata, 1990), are currently maintained. These concepts, applied to soil fertility and plant nutrition studies in general, and to mycorrhizosphere developments in particular, are summarized below.

The $\mathrm{N}$ available in nature is integrated into the only two stable $\mathrm{N}$ isotopes $\left({ }^{14} \mathrm{~N}\right.$ and $\left.{ }^{15} \mathrm{~N}\right)$, because the other four $\mathrm{N}$ isotopes are radioactive and have halflives very short. In the atmosphere (and in nature, in general) most $\mathrm{N}$ occurs as ${ }^{14} \mathrm{~N}(99.634 \%)$, while the natural abundance of ${ }^{15} \mathrm{~N}$ is only $0.366 \%$. The more o less constant ratio of ${ }^{15} \mathrm{~N} /{ }^{14} \mathrm{~N}$ in nature makes it possible to use these not radioactive $\mathrm{N}$ isotopes in plant nutrition studies based on the availability of materials (e. g. fertilizers) artificially enriched in ${ }^{15} \mathrm{~N}$ (i. e. with a known $\%{ }^{15} \mathrm{~N}$ atomic excess), as tracers. In this context, a basic concept in agronomy is that "when a plant is confronted with two or more sources of a nutrient, the nutrient uptake from each source is proportional to the amounts available in each source" (Zapata, 1990). Therefore, when a soil, having a \% ${ }^{15} \mathrm{~N}$ atomic excess at the natural abundance level, is supplemented with a ${ }^{15} \mathrm{~N}$-enriched $\left({ }^{15} \mathrm{~N}\right.$-labelled) 
fertilizer, the ${ }^{15} \mathrm{~N} /{ }^{14} \mathrm{~N}$ ratio in the available soil $\mathrm{N}$ pool will obviously increase, according to the known amount and richness of the added ${ }^{15} \mathrm{~N}$. Consequently, plants will take $\mathrm{N}$ from soil at the isotopic proportion provided by the new ${ }^{15} \mathrm{~N} /{ }^{14} \mathrm{~N}$ ratio. After growing in the target labelled soil the plant is analyzed for its isotopic N composition. Simple calculations allow us to quantify the amount of $\mathrm{N}$ in plant derived from soil or from the fertilizer. In addition, the isotope ${ }^{15} \mathrm{~N}$ can be used to quantify the apparent plant available $\mathrm{N}$ pool size, i.e. the $A_{N}$ value of the soil. This value represents the available amount of $\mathrm{N}$ for a given plant and is an inherent property of the soil, constant for any one set of experimental conditions (Zapata, 1990). However, when a given treatment able to produce changes in the $\mathrm{N}$ uptake properties of the roots allow plants to use $\mathrm{N}$ forms $\left(\operatorname{mostly}{ }^{14} \mathrm{~N}\right)$ in soil that the plant cannot use in absence of such a treatment, the $\mathrm{A}_{\mathrm{N}}$ value of the soil would increase.

Undoubtedly, the most widespread use of ${ }^{15} \mathrm{~N}$-aided methodologies is to measure $\mathrm{N}_{2}$ fixation by rhizobialegume symbiosis (Danso, 1986; Zapata, 1990). These techniques are based on the accepted principle that when a plant, either $\mathrm{N}_{2}$-fixing or non-fixing, are grown on a ${ }^{15} \mathrm{~N}$-labelled soil will take up ${ }^{15} \mathrm{~N}$ and ${ }^{14} \mathrm{~N}$ at a similar proportion, reflecting the ${ }^{15} \mathrm{~N} /{ }^{14} \mathrm{~N}$ ratio provided by the addition of the ${ }^{15} \mathrm{~N}$-labelled fertilizer to the soil. Because the $\mathrm{N}_{2}$-fixing plants have an additional source of available $\mathrm{N}$ from the atmosphere, in which the ${ }^{15} \mathrm{~N} /{ }^{14} \mathrm{~N}$ ratio is at the natural abundance level, the ratio ${ }^{15} \mathrm{~N} /{ }^{14} \mathrm{~N}$ will lower in the $\mathrm{N}_{2}$-fixing plant. Thereby, the ${ }^{15} \mathrm{~N}$ level in fixing plant is "diluted", and this is why the term "isotope dilution" was coined for these methodological approaches.

${ }^{15} \mathrm{~N}$-labelled fertilizers are used to measure $\mathrm{N}_{2}$ fixation by rhizobia-legume symbioses under field conditions, being this the only direct procedure which gives truly integrated measurements over a growing period (Zapata, 1990). For quantitative calculations, the lowering in ${ }^{15} \mathrm{~N} /{ }^{14} \mathrm{~N}$ ratio in the $\mathrm{N}_{2}$-fixing legumes with respect to the reference non-fixing crop is measured. As more efficient the rhizobial strain is the highest lowering of the ${ }^{15} \mathrm{~N} /{ }^{14} \mathrm{~N}$ ratio is produced (Danso, 1986; Zapata, 1990).

On another hand, root exudates of legume plants are known to be enriched in $\mathrm{N}$ compounds in comparison with those of non-legumes, thereby, legumes supply their rhizospheric soil with a surplus of $\mathrm{N}$ derived from fixation. This fact has a considerable relevance for both intercropping systems and natural plant communities. When legume plants are growing nearby non-legumes, these can tap $\mathrm{N}$ from the intermixed rhizospheres. This fact, known as "N-transfer from fixation", can be measured by using ${ }^{15} \mathrm{~N}$-based techniques (Danso, 1986). As the $\mathrm{N}$ in the exudates of the legume are derived from $\mathrm{N}_{2}$-fixation (at the natural abundance level in the ${ }^{15} \mathrm{~N} /{ }^{14} \mathrm{~N}$ ratio), this $\mathrm{N}$ result in a "dilution" of the ${ }^{15} \mathrm{~N} /{ }^{14} \mathrm{~N}$ ratio in a ${ }^{15} \mathrm{~N}$-labelled soil. Therefore, the non-fixing plants growing near legumes will show a lower ${ }^{15} \mathrm{~N} /{ }^{14} \mathrm{~N}$ ratio in their tissues with respect to other non-legume plants growing near other non-legume species.

As with the ${ }^{15} \mathrm{~N}$-based techniques, the basic ideas for the application of ${ }^{32} \mathrm{P}$-aided methodologies were established some years ago (Fardeau, 1993; Zapata and Axmann, 1995), but are still currently maintained. Isotopic $\left({ }^{32} \mathrm{P}\right.$ and $\left.{ }^{33} \mathrm{P}\right)$ dilution approaches have commonly been used for evaluating the exchange rates in phosphate equilibrium between the solution and the solid phases of soil (Fardeau, 1993), or to estimate the availability of $\mathrm{P}$ from fertilizer sources [including rock phosphate (RP)] (Zapata and Axmann, 1995; Zapata and Roy, 2004). The methodology involves labelling of the exchangeable pool of soil $\mathrm{P}$ with ${ }^{32} \mathrm{P}$-phosphate, being assumed that all 'labile' $\mathrm{P}$, and only this fraction, may attain isotopic exchange within a short-term experimental period (Fardeau, 1993). Plants are then grown in the soil under target 
agronomic managements (for instance, microbial inoculation). The isotopic composition, or "specific activity" (SA $={ }^{32} \mathrm{P} /{ }^{31} \mathrm{P}$ quotient) is then determined in plant tissues. The rationale is that if a given treatment induces a lowering in the SA in plant tissues with respect to the plants which have not received such treatment, the treated plants are using ${ }^{31} \mathrm{P}$ mobilised from sparingly available P sources, thereby "diluting" the ${ }^{32} \mathrm{P}$ content in plant.

5.4. The use of ${ }^{15} \mathrm{~N}$ to assess the impact of AM symbioses on $\mathrm{N}_{2}$-fixation by rhizobia-inoculated legumes

Since ${ }^{15} \mathrm{~N}$-based methodologies can be used for assessing the influence of any treatment on $\mathrm{N}_{2}$-fixation by rhizobia-inoculated legumes (Danso, 1986), these approaches were followed to ascertain the effect of AM fungi on symbiotic legumes. As far as we know, Barea et al. (1987) were the first to investigate these interactions under field conditions using ${ }^{15} \mathrm{~N}$-aided methodologies. They found that AM inoculation increased dry matter yield, $\mathrm{N}$ concentration and total $\mathrm{N}$ yield of the target nodulated legumes with respect to phosphate-added plants. A lower ${ }^{15} \mathrm{~N} /{ }^{14} \mathrm{~N}$ ratio was also found in the shoots of AM- and rhizobia-inoculated plants in comparison with those non-inoculated with AM fungi (but rhizobia-inoculated and phosphateadded). This indicated that AM inoculation enhances $\mathrm{N}_{2}$ fixation rates by the rhizobia-legume consortium. In addition, the use of ${ }^{15} \mathrm{~N}$ allowed to distinguish the origin of $\mathrm{N}$ in plant tissues and it was realized that both the amount of $\mathrm{N}$ derived from soil and that from fixation were higher in AM-inoculated plants than in either phosphate-added or non-treated controls. Therefore, in this tailored mycorrhizosphere field trial AM fungi improved $\mathrm{N}$ cycling and uptake by means of two processes of great importance in agroecosystems. These findings, based on the application of ${ }^{15} \mathrm{~N}$ dilution techniques, were further corroborated
(Barea et al., 1989a; 2002; Toro et al., 1998; Chalk et al., 2006).

The effect of AM fungi in helping N-transfer from $\mathrm{N}_{2}$-fixing to non-fixing plants can also be measured in tailored intermixed mycorrhizospheres, and it was shown that the AM symbiosis increased such "N-transfer from fixation" to non-legume plants. This has been demonstrated both in controlled conditions (Barea et al., 1989a) and under field conditions (Barea et al., 1989b; Requena et al., 2001).

\subsection{The use of ${ }^{32} P$ to evaluate the impact of interactions between AM fungi and PSB on P acquisition by plants}

The use of ${ }^{32} \mathrm{P}$-labelled soils has allowed us to conclude that AM- and non-AM plants show the same SA values, which means that they both use the same $P$ source, i. e. the available Pi pool (Joner and Jakobsen, 1995; Toro et al., 1997; Smith et al., 2003).

Indeed, ${ }^{32} \mathrm{P}$-tracer methodologies have been used to determine the contribution of AM fungi, in interaction with PSB, to plant $\mathrm{P}$ uptake from different $\mathrm{P}$ sources, including RP additions and using different plant species, mainly legumes (Raj et al., 1981; Toro et al., 1997; 1998; Barea et al., 2002; 2007). The general aims were to assess whether dual inoculation of PSB and AM fungi affect the SA of plants in RP-added, ${ }^{32} \mathrm{P}$-labelled, soils. These studies showed an increased biomass and $\mathrm{P}$ content of plants co-inoculated with $\mathrm{AM}$ and PSB. Indeed, the dually-inoculated plants have a lower SA with respect to those non-inoculated or singly-inoculated. This lowering of SA suggests that the plant used extra ${ }^{31} \mathrm{P}$, solubilised by the PSB, from sparingly available $P$ sources, either endogenous or added as RP. The PSB activity was coupled with the uptake of the solubilised P by the AM mycelium from the soil microhabitat were the PSB acted. By using isotope dilution concepts (Zapata and Roy 2004), the relative contribution of the different $\mathrm{P}$ sources of ${ }^{31} \mathrm{P}$ to 
plant nutrition (i. e. RP or endogenous P), as affected by microbial inoculation, was also determined (Barea et al., 2007). These studies concluded that co-inoculated plants have a greater access to $\mathrm{P}$ from RP, while plants inoculated only with PSB showed greater access only to the exchangeable soil $\mathrm{P}$ pool. As a general conclusion, it seems evident that plants dually-inoculated with both AM fungi and PSB appear to be more efficient for P supply compared to those that were non-inoculated or singly-inoculated.

Studies involving legumes, AM fungi, rhizobia and/ or PSB with RP application were carried out using simultaneously ${ }^{32} \mathrm{P}$ - and ${ }^{15} \mathrm{~N}$-aided methods (Toro et al., 1998; Barea et al., 2002). An improvement of $\mathrm{N}$ and $\mathrm{P}$ acquisition by plants was evidenced as a result of microbial interactions in the managed mycorrhizosphere.

5.6. Field testing of managed mycorrhizospheres as a basis for further agro-ecological applications

Developing field inoculation trials to exploit the benefit of tailored mycorrhizospheres at improving a sustainable nutrient acquisition by plants under agroecological conditions is a topic of current interest (Chalk et al., 2006; Azcón and Barea, 2010; Larimer et al., 2014; Borriss, 2015). However the information on these biotechnological practices is rather limited. Field validation of mycorrhizosphere management effectiveness through demonstrative assays carried out at an experimental dimension has been proposed as a preliminary step before a proper field application at an agro-ecological scale. Selected examples of field testing by demonstration experiments are first summarized. Then the developments necessary for a proper management of mycorrhizosphere services addressed to agronomical or ecological ends are discussed. The scenarios for applying mycorrhizosphere inoculation technology include both sustainable agriculture (synonymous with agroecology) and restoration of degraded ecosystems.

\subsection{Field testing of mycorrhizosphere management in agricultural systems}

As far as we know, Azcón-Aguilar et al. (1979) were the first to describe how dual inoculation of rhizobia and AM fungi improved significantly growth and nutrition of plants (Medicago sativa) in standard cultivation conditions, in comparison to single inoculation or to the basal effect of indigenous endophytes (non-inoculated controls). A new field experiment was designed to extend these first results using a soil with a higher level of fertility (AzcónAguilar and Barea, 1981). This field trial corroborated the effectiveness of dual inoculation of $M$. sativa plants with regard to dry matter production and nutrient content, upon serial harvests. Interestingly, in both field experiments the concentration of $\mathrm{N}$ in the tissues of AM-inoculated plants was higher than in plants inoculated only with rhizobia. This suggested for the first time a possible effect of AM fungi on $\mathrm{N}$ uptake from soil, as was further evidenced using ${ }^{15} \mathrm{~N}$-dilution techniques under field conditions (Barea et al., 1987). Actually, in this last field experiment it was shown that AM fungi increased both the amount of $\mathrm{N}$ derived from fixation in rhizobia-inoculated plants (Hedysarum coronarium) and the $\mathrm{N}$ derived from soil. Indeed, in another field trial, also using ${ }^{15} \mathrm{~N}$-aided methods, it was found that AM inoculation improved both N-fixation in rhizobia-inoculated Trifolium repens plants and $\mathrm{N}$-transfer to the associated Lolium perenne plants to improve pasture productivity (Barea et al., 1989b).

In any case, several aspects must be considered for the success of the inoculation of microbial symbionts on legume performance. First, is critical to identify and select the appropriate rhizobial strain/AM fungus 
combination to optimize their benefits on legume productivity (Azcón et al., 1991). In addition, it has also to be taken into account the fertility level of the soil. For example, the tripartite symbiosis was not effective and did not promote $\mathrm{N}_{2}$ fixation in soils with high levels of available P (Antunes et al., 2006; Zaidi and Khan, 2007; Lesueur and Sarr, 2008).

With regard to experiments analizing the interactive effects of PSB, AM fungi and rhizobia on plant performance under field conditions the information is scarce. In this context, Barea et al. (2002), after evidencing the positive effects of these multitrophic interactions on legume crops by applying isotopic ${ }^{32} \mathrm{P}$ and $\left.{ }^{15} \mathrm{~N}\right)$ dilution techniques under greenhouse conditions, extended their study in a field experiment. Using rhizobia-inoculated $M$. sativa as test plant, single- and dual-inoculation whith AM fungi and PSB (Enterobacter spp.) were combined with the addition of an organic amendment (a vermicompost) and/or RP. The inoculation with AM fungi significantly increased plant biomass, nodulation, $\mathrm{N}_{2}$-fixation, and $\mathrm{N}$ and $\mathrm{P}$ accumulation in the host plant. The inoculation with PSB improved AM effectiveness in soil dually amended with organic matter and RP. Therefore, the tailored mycorrhizosphere improved the agronomic efficiency of RP in the neutral test soil, resulting in a successful multitrophyc agro-technological tool (Barea et al., 2002).

\subsection{Field testing of mycorrhizosphere management in revegetation practices}

Apart from the experiments in agricultural scenarios, mycorrizosphere management has also been studied in field trials aimed at helping revegetation strategies for the recovery of degraded ecosystems (Barea et al., 2011). Two model experiments carried out in semiarid Mediterranean ecosystem of Southeast Spain are summarized.
In one of these experiments (Herrera et al., 1993) woody legumes, adapted to water-deficient and lownutrient environments, were inoculated with both $\mathrm{N}_{2}$-fixing bacteria and AM fungi. The target shrub legumes included two native (Anthyllis cytisoides and Spartium junceum) and four non-native (Robinia pseudoacacia, Acacia caven, Prosopis chilensis and Medicago arborea) species. The results of this fouryear trial showed that only the native shrub legumes were able to establish, survive and thrive under the local environmental conditions. It was also shown that the tailored mycorrhizosphere improved plant survival, out-planting performance and biomass production. A. cytisoides, a particularly droughttolerant, highly mycotrophic, legume species was selected for further revegetation studies.

Accordingly, for further developments, a strategy based on accelerating the process of natural revegetation was proposed by replanting randomlyspaced groups of target shrubs (A. cytisoides) from the natural succession, dually-inoculated with rhizobia and AM fungi. Transplanting of rhizosphere managed plantlets has to be performed by following the natural pattern and structure of undisturbed zones of the target degraded ecosystem. The idea is that transplanted seedlings with an optimized mycorrhizosphere not only will improve plant establishment and nutrient acquisition but will also act as "resource islands" serving as an inoculum source for the surrounding vegetation. In addition, it is fundamental that the establishment of mycorrhizosphere-tailored plants increase soil nutrient content and improve other physical-chemical properties, which define soil quality, therefore promoting an integral restoration of the target degraded ecosystem.

These ideas were tested in another study (Requena et al., 2001) where $A$. cytisoides seedlings produced under nursery conditions and endowed with appropriate $\mathrm{AM}$ and rhizobial symbionts, were transplanted to 
a target degraded area. The AM inoculum consisted of a mixture of five taxa of indigenous AM fungi representing the natural abundance and diversity in the target site. The tailored mycorrhizosphere not only enhanced the establishment and nutrient acquisition by the test plant but also increased the fertility and quality $(\mathrm{N}$ content, organic matter accumulation and formation of hydrostable soil aggregates) in the soil around A. cytisoides plants. A parallel study (Requena et al., 2001) also included Lavandula plant (a small shrub species from the natural succession of the site) associated to A. cytisoides. The same mycorrhizosphere management as in the core trial was used and the soil was labelled with ${ }^{15} \mathrm{~N}$ to measure $\mathrm{N}_{2}$-fixation and $\mathrm{N}$-transfer from the fixing $A$. cytisoides to the non-fixing Lavandula plants. Both processes were enhanced by the managed indigenous microsymbionts.

\subsection{Inoculum production technology for a successful tailoring of mycorrhizospheres}

A proper management of mycorrhizosphere services, addressed to help plant nutrition at agronomical scale, are hampered by some developments related to microbial inoculant technology. These include formulation studies, best practices for field applications and an in-deep analysis of factors that determine field inoculation success. While technology for the production of rhizobia and free-living beneficial bacteria are readily feasible and commercially available (Bashan et al., 2014; Ravensberg, 2015; Kamilova et al., 2015; Borriss, 2015), constraints for the production of AM inocula and the development of inoculation techniques have limited the exploitation of the AM potential. The difficulty to grow AM fungi in the absence of a host plant is a major limitation for massive inoculum production. The AM fungi inoculum production systems include the use of nursery plots, in vitro monoxenic root organ cultures and on-farm approaches (Ijdo et al., 2011; Sing et al., 2014). The AM inoculants have been applied in forestry, agriculture and horticulture, and several companies worldwide are producing these inocula which are now commercially available (Vosátka et al., 2008; Ijdo et al., 2011; Sing et al., 2014). The application of mycorrhizosphere technology is readily feasible when plants go through a nursery phase and are later on transplanted to the field having an optimized mycorrhizosphere, as it is the case with most plants of interest in horticulture, fruit-culture and forestry.

According to Salvioli and Bonfante (2013), the availability of novel molecular tools in AM research can help a better understanding on the still hidden aspects of AM fungi biology, a fundamental first step for selecting efficient fungal inoculants. Besides, these technologies would help to maximize the beneficial effect of the AM symbiosis in specific field conditions. A key issue is the development of the appropriate methodology for analyzing the establishment, persistence and effectiveness of AM fungal inoculants in the field. Pellegrino et al. (2012) approached these aspects by using molecular genetic tracing techniques which allowed to determine the inoculation success. Indeed, these authors also evidenced a sustained positive effect on plants ( $M$. sativa) yield supporting the fundamental role on AM fungal inoculation in agriculture. With regard to the control of the factors, which determine inoculation success and AM fungal persistence in soils, Verbruggen et al., (2013) identified some of these factors namely the AM fungus and plant choice, management practices and timing of inoculation. A recent book (Solaiman et al., 2014) gives comprehensive information on the use of AM fungi in sustainable agriculture and land restoration. 


\section{Concluding remarks}

Both plant mutualistic symbionts and saprophytic microorganisms living at the root-soil interfaces, the rhizosphere, or in the plant-associated soil, are recognized as essential drivers of nutrient cycling, availability and capture. The ubiquitous AM fungi, after establishing the AM symbiosis with most plant species, are known to enhance the ability of the plant for nutrient uptake. Besides, some saprophytic rhizobacteria are recognized for their abilities to propel nitrogen (N)-fixation and/or phosphorus (P) mobilization, two fundamental processes for sustaining plant productivity. Mycorrhiza establishment changes the biological and physicalchemical properties of the rhizosphere, developing the so-called mycorrhizosphere, where AM fungi interact with other microorganisms involved in nutrient cycling. Particularly relevant is the mycorrhizosphere of legume plants since it also involves the symbiosis with $\mathrm{N}_{2}$-fixing nodulating bacteria (rhizobia). Consolidated information supports that opportunity exists to exploit the interactive effects of phosphate mobilizing bacteria, $\mathrm{N}_{2}$ - fixing rhizobia and AM-fungi, through tailored management of the mycorrhizosphere, thereby benefiting $\mathrm{P}$ and $\mathrm{N}$ cycling and plant nutrition.

\section{Acknowledgements}

We thank support from the Andalucian (Spain) Government (project P11-CVI-7640) and CSIC (Intramural project 201440E099).

\section{References}

Altieri, M.A. 2004. Linking ecologists and traditional farmers in the search for sustainable agriculture. Front. Ecol. Environ. 2, 35-42.
Antoun, H. 2012. Beneficial microorganisms for the sustainable use of phosphates in agriculture. Proc. Engineer. 46, 62-67.

Antunes, P.M., de Varennes, A., Zhang T., Goss, M.J. 2006. The tripartite symbiosis formed by indigenous arbuscular mycorrhizal fungi, Bradyrhizobium japonicum and soya bean under field conditions. J. Agron. Crop. Sci. 192, 373-378.

Asai, T. 1944. Die bedeutung der mikorrhiza für das pflanzenleben. Jpn. J. Bot. 12.

Azcón, R., Barea, J.M. 2010. Mycorrhizosphere interactions for legume improvement. In: M.S. Khan, A. Zaidi, J.Musarrat (eds). Microbes for legume improvement. Springer-Verlag, pp: 237-271.

Azcón, R., Barea, J.M., Hayman, D.S. 1976. Utilization of rock phosphate in alkaline soils by plant inoculated with mycorrhizal fungi and phosphate-solubilizing bacteria. Soil Biol. Biochem. 8, 135-138.

Azcón, R., Rubio, R., Barea, J.M. 1991. Selective interactions between different species of mycorrhizal fungi and Rhizobium meliloti strains, and their effects on growth, $\mathrm{N}_{2}$ fixation $\left(\mathrm{N}^{15}\right)$ in Medicago sativa at four salinity levels. New Phytol. 117, 399-404.

Azcón-Aguilar, C., Azcón, R., Barea, J.M. 1979. Endomycorrhizal fungi and Rhizobium as biological fertilizers for Medicago sativa in normal cultivation. Nature 279, 325-327.

Azcón-Aguilar, C., Barea, J.M. 1981. Field inoculation of Medicago with VA mycorrhiza and Rhizobium in phosphate-fixing agricultural soil. Soil Biol. Biochem. 13, 19-22.

Bashan, Y., de-Bashan, L.E., Prabhu, S.R., Hernandez, J.-P. 2014. Advances in plant growth-promoting bacterial inoculant technology: formulations and practical perspectives (1998-2013). Plant Soil $378,1-33$. 
Bago, B., Azcón-Aguilar, C., Goulet, A., Piché, Y. 1998. Branched adsorbing structure (BAS): a feature of the extraradical mycelium of symbiotic arbuscular mycorrhizal fungi. New Phytol. 139, 375-88.

Bago, B., Pfeffer, P.E., Zipfel, W., Lammers, P., Shachar-Hill, Y. 2002. Tracking metabolism and imaging transport in arbuscular mycorrhizal fungi. Metabolism and transport in AM fungi. Plant Soil 244, 189-197.

Barea, J.M. 2010. Mycorrhizas and agricultural fertility. In: A. González-Fontes, A. Gárate, I.Bonilla (eds). Agricultural Sciences: Topics in Modern Agriculture. Stadium Press, USA, pp. 257-274.

Barea, J.M., Azcón, R., Azcón-Aguilar, C. 1989 b. Time-course of $\mathrm{N}_{2}$ fixation $\left({ }^{15} \mathrm{~N}\right)$ in the field by clover growing alone or in mixture with ryegrass to improve pasture productivity, and inoculated with vesicular-arbuscular mycorrhizal fungi. New Phytol. 112, 399-404.

Barea, J.M., Azcón, R., Azcón-Aguilar, C. 2005. Interactions between mycorrhizal fungi and bacteria to improve plant nutrient cycling and soil structure. In: F. Buscot, A.Varma (eds). Microorganisms in Soils: Roles in Genesis and Functions. Springer-Verlag, Berlin, pp: 195-212.

Barea, J.M., Azcón-Aguilar, C. 2013. Evolution, biology and ecological effects of arbuscular mycorrhiza. In: A.F. Camisao, C.C. Pedroso (eds). Symbiosis: Evolution, Biology and Ecological Effects. Nova Science, pp: 1-34.

Barea, J.M., Azcón-Aguilar, C., Azcón, R. 1987. Vesicular-arbuscular mycorrhiza improve both symbiotic $\mathrm{N}_{2}$-fixation and $\mathrm{N}$ uptake from soil as assessed with a ${ }^{15} \mathrm{~N}$ technique under field conditions. New Phytol. 106, 717-725.
Barea, J.M., El-Atrach, F., Azcón, R. 1989a Mycorrhiza and phosphate interactions as affecting plant development, $\mathrm{N}_{2}$ fixation, $\mathrm{N}$-transfer and $\mathrm{N}$-uptake from soil in legume grass mixtures by using a $\mathrm{N}^{15}$ dilution technique. Soil Biol. Biochem. 21, 581-589.

Barea, J.M., Palenzuela, J., Cornejo, P., SánchezCastro, I. Navarro-Fernández C., Lopéz-García A., Estrada, B., Azcón R., Ferrol N., AzcónAguilar C. 2011. Ecological and functional roles of mycorrhizas in semi-arid ecosystems of Southeast Spain. J. Arid Environm. 75: 1292-1301.

Barea, J.M., Pozo, M.J., Azcón, R., Azcón-Aguilar, C. 2013a. Microbial interactions in the rhizosphere In: F.J. de Bruijn (ed.). Molecular Microbial Ecology of the Rhizosphere, vol 1. John Wiley \& Sons, USA, pp: 29-44.

Barea, J.M., Pozo, M.J., López-Ráez, J.A., Aroca, R., Ruíz-Lozano, J.M., Ferrol, N., Azcón, R., AzcónAguilar, C. 2013b. Arbuscular Mycorrhizas and their significance in promoting soil-plant systems sustainability against environmental stresses In: B. Rodelas, J. González-López (eds). Beneficial Plant-Microbial Interactions: Ecology and Applications. USA, CRC Press, pp: 353-387.

Barea, J.M., Richardson, A.E. 2015. Phosphate mobilisation by soil microorganisms. In: B. Lugtenberg (ed). Principles of Plant-Microbe Interactions. Springer, pp: 225-234.

Barea, J.M., Toro, M., Azcón, R. 2007. The use of ${ }^{32} \mathrm{P}$ isotopic dilution techniques to evaluate the interactive effects of phosphate-solubilizing bacteria and mycorrhizal fungi at increasing plant $\mathrm{P}$ availability. In: E. Velázquez, C. RodríguezBarrueco (eds). Int. Meet. Microbial Phosphate Solubilization. Series: Developments in Plant and Soil Sciences. Springer, pp: 223-227. 
Barea, J.M., Toro, M., Orozco, M.O., Campos, E., Azcón, R. 2002. The application of isotopic ( $\mathrm{P}^{32}$ and $\mathrm{N}^{15}$ ) dilution techniques to evaluate the interactive effect of phosphate-solubilizing rhizobacteria, mycorrhizal fungi and Rhizobium to improve the agronomic efficiency of rock phosphate for legume crops. Nutrient Cycling Agroecosyst. 63, 35-42.

Barret, M., Tan, H., Egan, F., Morrissey, J.P., Reen, J., O’Gara, F. 2013. Exploiting new systems-based strategies to elucidate plant-bacterial interactions in the rhizosphere. In: F.J. de Bruijn (ed.). Molecular Microbial Ecology of the Rhizosphere, vol 1. John Wiley \& Sons, USA, pp: 57-68.

Benedetto, A., Magurno, F., Bonfante, P., Lanfranco, L. 2005. Expression profiles of a phosphate transporter gene (GmosPT) from the endomycorrhizal fungus Glomus mosseae. Mycorrhiza 15, 620-627.

Bonfante, P., Desirò, A. 2015. Arbuscular mycorrhizas: the lives of beneficial fungi and their plant host. In: B. Lugtenberg (ed). Principles of Plant-Microbe Interactions. Springer, pp: 235-245.

Bonfante, P., Genre, A. 2008. Plants and arbuscular mycorrhizal fungi: an evolutionary-developmental perspective. Trends Plant Sci. 13, 492-498.

Bonfante, P., Genre, A. 2010. Mechanisms underlying beneficial plant- fungus interactions in mycorrhizal symbiosis Nat. Commun. 1, 48.

Borie, F., Rubio, R., Morales, A., Curaqueo, G., Cornejo, P. 2010. Arbuscular mycorrhizae in agricultural and forest ecosystems in Chile. J. Soil Sci. Plant Nut. 10, 185-206.

Borriss, R. 2015. Towards a new generation of commercial microbial disease control and plant growth promotion products. In: B. Lugtenberg (ed). Principles of Plant-Microbe Interactions. Springer, pp: 329-337.
Browne, P., Barret, M., Morrissey, J.P., O'Gara, F. 2013. Molecular-based strategies to exploit the inorganic phosphate-solubilization ability of Pseudomonas in Sustainable Agriculture. In: F.J. de Bruijn (ed.). Molecular Microbial Ecology of the Rhizosphere, vol 2. Wiley Blackwell, USA, pp: 615-628.

Brundrett, M.C. 2002. Coevolution of roots and mycorrhizas of land plants. New Phytol. 154, 275-304.

Brundrett, M.C. 2009. Mycorrhizal associations and other means of nutrition of vascular plants: understanding the global diversity of host plants by resolving conflicting information and developing reliable means of diagnosis. Plant Soil 320, 37-77.

Chalk, P.M., Souza, R.D., Urquiaga, S., Alves, B.J.R., Boddey, R.M. 2006. The role of arbuscular mycorrhiza in legume symbiotic performance. Soil Biol. Biochem. 38, 2944-2951.

Courty, P.E., Smith, P., Koegel, S., Redecker, D., Wipf, D. 2015. Inorganic nitrogen uptake and transport in beneficial plant root-microbe interactions. Crit. Rev. Plant Sci. 34, 4-16.

Danso, S.K.A. 1986. Review, estimation of $\mathrm{N}_{2}$ fixation by isotope dilution: an appraisal of techniques involving ${ }^{15} \mathrm{~N}$ enrichment and their application. Soil Biol. Biochem. 18, 243-244.

de Bruijn, F.J. 2015. Biological nitrogen fixation. In: B. Lugtenberg (ed). Principles of Plant-Microbe Interactions. Springer, pp: 215-224.

Dobbelaere, S., Croonenborghs, A., Thys, A., Ptacek, D., Vanderleyden, J., Dutto, P., Labandera-González, C., Caballero-Mellado, J., Aguirre, J.F., Kapulnik, Y., Brener, S., Burdman, S., Kadouri, D., Sarig, S., Okon, Y. 2001. Responses of agronomically important crops to inoculation with Azospirillum. Aust. J. Plant Physiol. 28, 871-879. 
Dos Santos, P.C., Fang, Z., Mason, S.W., Setubal, J.C., Dixon, R. 2012. Distribution of nitrogen fixation and nitrogenase-like sequences amongst microbial genomes. BMC Genomics 13, 162-162.

Elser, J.J. 2011. A world awash with nitrogen. Science 334, 1504-1505.

Fardeau, J.C. 1993. Available soil phosphate its representation by a functional multiple compartment model. Agronomie 13, 317-331.

Ferrol, N., Pérez-Tienda, J. 2009. Coordinated nutrient exchange in arbuscular mycorrhiza. In: C. AzcónAguilar, J.M. Barea, S.Gianinazzi, V.GianinazziPearson (eds). Mycorrhizas: Functional Processes and Ecological Impact. Springer-Verlag, pp: $73-$ 87.

Finlay, R.D. 2008. Ecological aspects of mycorrhizal symbiosis: with special emphasis on the functional diversity of interactions involving the extraradical mycelium. J. Exp. Bot. 59: 1115-1126.

Franken, P., Waschke, A., Requena, N. 2012. Molecular approaches to arbuscular mycorrhiza functioning. In: B. Hock (ed). The Mycota, a comprehensive treatise on fungi as experimental systems for basic and applied research. Springer, pp: 22-37.

Frey-Klett, P., Garbaye, J., Tarkka, M. 2007. The mycorrhiza helper bacteria revisited. New Phytol. $176,22-36$.

Genre, A., Bonfante, P. 2010. The making of symbiotic cells in arbuscular mycorrhizal roots. In H. Koltai and Y. Kapulnik (eds). Arbuscular mycorrhizas: Physiology and function. Springer, pp. 57-71.

Gianinazzi, S., Gollotte, A., Binet, M.N., van Tuinen, D., Redecker, D., Wipf, D. 2010. Agroecology: The key role of arbuscular mycorrhizas in ecosystem services. Mycorrhiza 20, 519-530.
Gianinazzi-Pearson, V., van Tuinen, D., Wipf, D.,Dumas-Gaudot, E., Recorbet, G., Lyu, Y. Doidy, J., Redecker, D., Ferrol, N. 2012. Exploring the genome of Glomeromycotan fungi. In: B. Hock (ed). The Mycota, a comprehensive treatise on fungi as experimental systems for basic and applied research. Springer, pp: 1-21.

Gomez, S.K., Javot, H., Deewatthanawong, P., TorresJerez, I., Tang, Y., Blancaflor, E.B., Udvardi, M.K., Harrison, M.J. 2009. Medicago truncatula and Glomus intraradices gene expression in cortical cells harboring arbuscules in the arbuscular mycorrhizal symbiosis. BMC Plant Biol. 9, 10.

Govindarajulu, M., Pfeffer, P.E., Jin, H.R., Abubaker, J., Douds, D.D., Allen, J.W., Bucking, H., Lammers, P.J., Shachar-Hill, Y. 2005. Nitrogen transfer in the arbuscular mycorrhizal symbiosis. Nature 435, 819-823.

Guether, M., Neuhauser, B., Balestrini, R., Dynowski, M., Ludewig, U., Bonfante, P. 2009. A mycorrhizal-specific ammonium transporter from Lotus japonicus acquires nitrogen released by arbuscular mycorrhizal fungi. Plant Physiol $150,73-83$.

Gutjahr, C., Parniske M. 2013. Cell and developmental biology of arbuscular mycorrhiza symbiosis. Annu. Rev. Cell Dev. Biol.29, 593-617.

Gutiérrez-Mañero, J., Ramos-Solano, B. 2010. Bacteria and Agriculture. In: A. González-Fontes, A. Gárate, I.Bonilla (eds). Agricultural Sciences: Topics in Modern Agriculture. Stadium Press, USA, pp: 275-289.

Haage, K., Parniske, M. 2013. Molecular mechanisms goberning arbuscular mycorrhiza development and function. In: F.J. de Bruijn (ed.). Molecular Microbial Ecology of the Rhizosphere, vol 1. Wiley Blackwell, USA, pp: 459-465. 
Harrison, M. J. 2012. Cellular programs for arbuscular mycorrnizal simbiosis. Curr. Opin. Plant Biol. 15, 691-698.

Harrison, M. J., Dewbre, G.R., Liu, J. 2002. A phosphate transporter from Medicago truncatula involved in the acquisition of phosphate released by arbuscular mycorrhizal fungi. Plant Cell 14, 2413-2429.

Harrison, M. J., van Buuren, M. L., 1995. A phosphate transporter from the mycorrhizal fungus Glomus versiforme. Nature, 378, 626-629.

Hartmann, A., Bashan, Y. 2009. Ecology and application of Azospirillum and other plant growth-promoting bacteria (PGPB) - Special Issue. Eur. J. Soil Biol. 45, 1-2.

Helber, N., Wippel, K., Sauer, N., Schaarschmidt, S., Hause, B., Requena, N. 2011. A versatile monosaccharide transporter that operate in the arbuscular mycorrhizal fungus Glomus sp. is crucial for the symbiotic relationship with plants. Plant Cell 23, 3812-3823.

Hirsch, P.R., Mauchline, T.H., Clark, I.M. 2013. Culture-independent molecular approaches to microbial ecology in soil and the rhizosphere. In: F.J. de Bruijn (ed). Molecular Microbial Ecology of the Rhizosphere, vol 1. Wiley Blackwell, USA, pp: 45-55.

Herrera, M.A., Salamanca, C.P., Barea, J.M. 1993. Inoculation of woody legumes with selected arbuscular mycorrhizal fungi and rhizobia to recover desertified mediterranean ecosystems. Appl. Environ. Microbiol. 59, 129-133.

Honrubia, M. 2009. The Mycorrhizae: a plant-fungus relation that has existed for more than 400 million years. Anal. Jardin Botanico de Madrid 66, 133-144.

Ijdo, M., Cranenbrouck, S., Declerck, S. 2011. Methods for large-scale production of AM fungi: past, present, and future. Mycorrhiza 21, 1-16.
Janse, J.M. 1896. Les endophytes radicaux des quelques plantes Javanaises. Annales du Jardin Botanique Buitenzorg 14, 53-212.

Jansa, J., Mozafar, A., Frossard, E. 2003. Longdistance transport of $\mathrm{P}$ and $\mathrm{Zn}$ through the hyphae of an arbuscular mycorrhizal fungus in symbiosis with maize. Agronomie 23, 481-488.

Jayaraman, D., Forshey, K.L., Grimsrud, P.A., Ane, J.-M. 2012. Leveraging proteomics to understand plantmicrobe interactions. Frontiers in Plant Sci. 3.

Jeffries, P., Barea, J.M. 2012. Arbuscular Mycorrhiza - a key component of sustainable plant-soil ecosystems. In: B. Hock (ed). The Mycota, a comprehensive treatise on fungi as experimental systems for basic and applied research. Springer, pp: 51-75.

Jeffries, P., Gianinazzi, S., Perotto, S., Turnau, K., Barea, J.M. 2003. The contribution of arbuscular mycorrhizal fungi in sustainable maintenance of plant health and soil fertility. Biol. Fertil. Soils 37, $1-16$.

Joner, E.J., Jakobsen, I. 1995. Growth and extracellular phosphatase activity of arbuscular mycorrhizal hyphae as influenced by soil organic matter. Soil Biol. Biochem. 27, 1153-1159.

Jones, F.R. 1924. A mycorrhizal fungus in the roots of legumes and some other plants. J. Agr. Res. 29, 459-470.

Jorquera, M.A., Hernandez, M.T., Rengel, Z., Marschner, P., de la Luz Mora, M., 2008. Isolation of culturable phosphobacteria with both phytatemineralization and phosphate-solubilization activity from the rhizosphere of plants grown in a volcanic soil. Biol. Fert. Soil. 44, 1025-1034.

Kamilova, F., Okon, Y., de Weert, S., Hora, K. 2015. Commercialization of microbes: manufacturing, inoculation, best practice for objective field testing, and registration. In: B. Lugtenberg 
(ed). Principles of Plant-Microbe Interactions. Springer, pp: 319-327.

Karandashov, V. Bucher, M. 2005. Symbiotic phosphate transport in arbuscular mycorrhizas. Trends Plant Sci. 10, 22-29.

Kaschuk, G., Kuyper, T.W., Leffelaar, P.A., Hungria, M., Giller, K.E. 2009. Are the rates of photosynthesis stimulated by the carbon sink strength of rhizobial and arbuscular mycorrhizal symbioses? Soil Biol. Biochem. 41, 1233-1244.

Kiers, E.T., Duhamel, M., Beestty, Y., Mensah, J.A., Franken, O., Verbruggen, E., Fellbaum, C.R., Kowalchuk, G.A., Hart, M.M., Bago, A., Palmer, T.M., West, S.A., Vandenkoornhuyse, P., Jansa, J., Bücking, H. 2011. Reciprocal rewards stabilize cooperation in the mycorrhizal symbiosis. Science $333,880-882$.

Kikuchi, Y., Hijikata, N., Yokoyama, K., Ohtomo, R., Handa, Y., Kawaguchi, M., Saito, K., Ezawa, T. 2014. Polyphosphate accumulation is driven by transcriptome alterations that lead to nearsynchronous and near-equivalent uptake of inorganic cations in an arbuscular mycorrhizal fungus. New Phytol. 204, 638-649.

Kobae, Y., Tamura, Y., Takai, S., Banba, M., Hata, S. 2010. Localized expression of arbuscular mycorrhiza-inducible ammonium transporters in soybean. Plant Cell Physiol. 51, 1411-1415.

Koegel, S., Ait Lahmidi, N., Arnould, C., Chatagnier, O., Walder, F., Ineichen, K., Boller, T., Wipf, D., Wiemken, A., Courty, P.-E. 2013. The family of ammonium transporters (AMT) in Sorghum bicolor: two AMT members are induced locally, but not systemically in roots colonized by arbuscular mycorrhizal fungi. New Phytol. 198, 853-865.

Koide, R.T., Mosse, B. 2004. A history of research on arbuscular mycorrhiza. Mycorrhiza 14, 145-163.

Larimer, A.L., Clay, K., Bever, J.D. 2014. Synergism and context dependency of interactions between arbuscular mycorrhizal fungi and rhizobia with a prairie legume. Ecology 95, 1045-1054.

Larsen, J., Cornejo, P., Miguel Barea, J. 2009. Interactions between the arbuscular mycorrhizal fungus Glomus intraradices and the plant growth promoting rhizobacteria Paenibacillus polymyxa and P-macerans in the mycorrhizosphere of Cucumis sativus. Soil Biol. Biochem. 41, 286292.

Lesueur, D., Sarr, A. 2008. Effects of single and dual inoculation with selected microsymbionts (rhizobia and arbuscular mycorrhizal fungi) on field growth and nitrogen fixation of Calliandra calothyrsus Meissn. Agroforestry Systems 73, $37-45$.

Liu, A., Hamel, C., Hamilton, R.I., Ma, B.L., Smith, D.L. 2000. Acquisition of $\mathrm{Cu}, \mathrm{Zn}, \mathrm{Mn}$ and $\mathrm{Fe}$ by mycorrhizal maize (Zea mays L.) grown in soil at different $\mathrm{P}$ and micronutrient levels. Mycorrhiza 9, 331-336.

López-Pedrosa, A., González-Guerrero, M., Valderas, A., Azcón-Aguilar, C., Ferrol, N. 2006. GintAMT1 encodes a functional high-affinity ammonium transporter that is expressed in the extraradical mycelium of Glomus intraradices. Fungal Genet. Biol. 43, 102-110.

López-Ráez, J.A., Pozo, M.J., García-Garrido, J.M. 2011. Strigolactones: a cry for help in the rhizosphere. Botany 89, 513-522.

Lugtenberg, B. 2015. Life of microbes in the rhizosphere. In: B. Lugtenberg (ed). Principles of Plant-Microbe Interactions. Springer, pp: 7-15.

Mäder, P., Vierheilig, H., Streitwolf-Engel, R., Boller, T., Frey, B., Wiemken, A. 2000. Transport of ${ }^{15} \mathrm{~N}$ from a soil compartment separated by a polytetrafluoroethylene membrane to plant roots via the hyphae of arbuscular mycorrhizal fungi. New Phytol. 146,155-61. 
Maillet, F., Poinsot, V., André, O., Puech-Pagés, V., Haouy, A., Gueunier, M., Cromer, L., Giraudet, D., Formey, D., Niebel, A., Martinez, E.A., Driguez, H., Bécard, G., Dénarié, J. 2011. Fungal lipochitooligosaccharide symbiotic signals in arbuscular mycorrhiza. Nature 469, 58-64.

Maldonado-Mendoza, I. E., Dewbre, G. R., Harrison, M. J. 2001. A phosphate transporter gene from the extra-radical mycelium of an arbuscular mycorrhizal fungus Glomus intraradices is regulated in response to phosphate in the environment. Mol. Plant-Microbe Interact. 14, 1140-1148.

Marschner, P. 2008. The role of rhizosphere microorganisms in relation to $\mathrm{P}$ uptake by plants. In: P.J. White, J. Hammond, (eds). The Ecophysiology of Plant-Phosphorus Interactions. Series: Plant Ecophysiology, Vol. 7 Springer, pp: $165-176$

Martinez-Viveros, O., Jorquera, M.A., Crowley, D.E., Gajardo, G., Mora, M.L. 2010. Mechanisms and practical considerations involved in plant growth promotion by rhizobacteria. J. Soil Sci. Plant Nut. 10, 293-319.

Miyauchi, H.M.Y., Lima, D.S., Nogueira, M.A., Lovato, G.M., Murate, L.S., Cruz, M.F., Ferreira, J.M., Zangaro, W., Andrade, G. 2008. Interactions between diazotrophic bacteria and mycorrhizal fungus in maize genotypes. Scientia Agricola 65, 525-531.

Mundstock, A., de Carvalho, X., de Castro Tavares, R., Cardoso, I.M., Kuyper, T.W. 2010. Mycorrhizal associations in agroforestry systems. In: Dion, P., (Ed.), Soil Biology and Agriculture in the Tropics, Soil Biology 21. Springer-Verlag, pp: 185-208.

Olivares, J., Bedmar,E. J., and Sanjuán, J. 2013. Biological nitrogen fixation in the context of global change. Mol. Plant-Microbe Interact. 26, 486-494.
Parniske, M. 2008. Arbuscular mycorrhiza: the mother of plant root endosymbioses. Nat. Rev. Microbiol. 6, 763-775.

Pellegrino, E., Turrini, A., Gamper, H.A., Cafà, G., Bonari, E., Young, J.P.W., Giovannetti, M. 2012. Establishment, persistence and effectiveness of arbuscular mycorrhizal fungal inoculants in the field revealed using molecular genetic tracing and measurement of yield components. New Phytol. $194,810-822$.

Pérez-Tienda, J., Corrêa, A., Azcón-Aguilar, C., Ferrol, N. 2014. Transcriptional regulation of host $\mathrm{NH}^{+}$transporters and GS/GOGAT pathway in arbuscular mycorrhizal rice roots. Plant Physiol. Biochem. 75, 1-8.

Pérez-Tienda, J., Testillano, P.S., Balestrini, R., Fiorilli, V., Azcón-Aguilar, C., Ferrol, N. 2011. GintAMT2, a new member of the ammonium transporter family in the arbuscular mycorrhizal fungus Glomus intraradices. Fungal Genet. Biol. 48, 1044-1055.

Pivato, B., Offre, P., Marchelli, S., Barbonaglia, B., Mougel, C., Lemanceau, P., Berta, G. 2009. Bacterial effects on arbuscular mycorrhizal fungi and mycorrhiza development as influenced by the bacteria, fungi, and host plant. Mycorrhiza 19, 81-90.

Pozo, M., López-Ráez, J., Azcón-Aguilar, C., GarcíaGarrido, J. 2015. Phytohormones as integrators of environmental signals in the regulation of mycorrhizal symbioses. New Phytol. 205, 14311436 .

Raj, J., Bagyaraj, J., Manjunath, A. 1981. Influence of soil inoculation with vesicular-arbuscular mycorrhiza and a phosphate-dissolving bacterium on plant growth and ${ }^{32} \mathrm{P}$-uptake. Soil Biol. Biochem. 13, 105-108.

Ravensberg, W.J. 2015. Commercialisation of microbes: Present situation and future prospects. In: B. Lugtenberg (ed). Principles of Plant- 
Microbe Interactions. Microbes for Sustainable Agriculture. Springer, pp: 309-317.

Requena, N., Pérez-Solis, E., Azcón-Aguilar, C., Jeffries, P., Barea, J.M. 2001. Management of indigenous plant-microbe symbioses aids restoration of desertified ecosystems. Appl. Environ. Microbiol. 67, 495-498.

Richardson, A.E. 2007. Making microorganisms mobilize soil phosphorus. In: E.Velázquez, C. Rodríguez-Barrueco (eds). First International Meeting on Microbial Phosphate Solubilization, vol 102. Developments in Plant and Soil Sciences. Springer, pp: 85-90.

Richardson, A.E., Barea, J.M., McNeill, A.M., Prigent-Combaret, C. 2009. Acquisition of phosphorus and nitrogen in the rhizosphere and plant growth promotion by microorganisms. Plant Soil 321, 305-339.

Russo, A., Felici, C., Toffanin, A., Gotz, M., Collados, C., Barea, J.M., Moenne-Loccoz, Y., Smalla, K., Vanderleyden, J., Nuti, M. 2005. Effect of Azospirillum inoculants on arbuscular mycorrhiza establishment in wheat and maize plants. Biol. Fertil. Soils 41, 301-309.

Salvioli, A., Bonfante, P. 2013. Systemic biology and "omics" tool: a cooperation for next- generation mycorrhizl studies. Plant Sci. 203-204, 107-114.

Schüßler, A., Gehrig, H., Schwarzott, D., Walker, C. 2001. Analysis of partial Glomales SSU rRNA gene sequences: implications for primer design and phylogeny. Mycol. Res. 105, 5-15.

Schüßler, A., Walker, C. 2011. Evolution of the 'plantsymbiotic' fungal phylum, Glomeromycota. In: S. Pöggeler, J. Wöstemeyer (eds). Evolution of fungi and fungal-like organisms Springer-Verlag, pp: 163-185.

Singh, S., Srivastava, K. Sharma, S., Sharma. A.K. 2014. Mycorrhizal inoculum production. In: Z. M.Solaiman, L. K.Abbott, A. Varma, 2014.
Mycorrhizal fungi: use in sustainable agriculture and land restoration. Soil Biology, vol. 41. Springer-Verlag, pp: 67-80.

Smith, S.E., Read, D.J., 2008. Mycorrhizal Symbiosis. 3rd Edn. Elsevier, Academic Press, $787 \mathrm{p}$.

Smith, S.E., Smith, F.A. 2011. Roles of arbuscular mycorrhizas in plant nutrition and growth: new paradigms from cellular to ecosystem scales. Ann. Rev. Plant Biol. 62, 227-250.

Smith, S.E., Smith, F.A. 2012. Fresh perspectives on the roles of arbuscular mycorrhizal fungi in plant nutrition and growth. Mycologia 104, 1-13.

Smith, S.E., Smith, F.A., Jakobsen, I. 2003. Mycorrhizal fungi can dominate phosphate supply to plants irrespective of growth responses. Plant Physiol. 133, 16-20.

Solaiman, Z. M., Abbott, L. K., Varma, A. 2014. Mycorrhizal fungi: use in sustainable agriculture and land restoration. Soil Biology, vol. 41. Springer-Verlag, $415 \mathrm{p}$.

Tamura, Y., Kobae, Y., Mizuno, T., Hata, S. 2012. Identification and expression analysis of arbuscular mycorrhiza-inducible phosphate transporter genes of soybean. Biosci. Biotechnol. Biochem. 76, 309-313.

Toljander, J.F., Lindahl, B.D., Paul, L.R., Elfstrand, M., Finlay, R.D. 2007. Influence of arbuscular mycorrhizal mycelial exudates on soil bacterial growth and community structure. FEMS Microbiol. Ecol. 61, 295-304.

Tobar, R. M., Azcón, R., Barea, J.M. 1994a. Improved nitrogen uptake and transport from ${ }^{15} \mathrm{~N}$-labelled nitrate by external hyphae of arbuscular mycorrhiza under water-stressed conditions. New Phytol. 126, 119-122.

Tobar, R. M., Azcón, R., Barea, J.M. 1994b.The improvement of plant $\mathrm{N}$ acquisition from an 
ammonium-treated, drought-stressed soil by the fungal symbiont in arbuscular mycorrhizae. Mycorrhiza 4,105-108.

Toro, M., Azcón, R., Barea, J.M. 1997. Improvement of arbuscular mycorrhiza development by inoculation of soil with phosphate-solubilizing rhizobacteria to improve rock phosphate bioavailability $\left(\mathrm{P}^{32}\right)$ and nutrient cycling. Appl. Environ. Microbiol. 63, 4408-4412.

Toro, M., Azcón, R., Barea, J.M. 1998. The use of isotopic dilution techniques to evaluate the interactive effects of Rhizobium genotype, mycorrhizal fungi, phosphate-solubilizing rhizobacteria and rock phosphate on nitrogen and phosphorus acquisition by Medicago sativa. New Phytol. 138, 265-273.

van der Heijden, M. G. A., Martin, F. M., Selosse, M. A., Sanders, I. R. 2015. Mycorrhizal ecology and evolution: the past, the present, and the future. New Phytol. 205, 1406-1423.

Vázquez, M.M., Cesar, S., Azcón, R., Barea, J.M. 2000. Interactions between arbuscular mycorrhizal fungi and other microbial inoculants (Azospirillum, Pseudomonas, Trichoderma) and their effects on microbial population and enzyme activities in the rhizosphere of maize plants. Appl. Soil Ecol. 15, 261-272.

Verbruggen, E., van der Heijden, M.G.A., Rillig, M.C., Kiers, E.T. 2013. Mycorrhizal fungal establishment in agricultural soils: factors determining inoculation success. New Phytol. 197, 1104-1109.

Veresoglou, S. D., Chen, B., Matthias C. Rillig, M. C. 2012. Arbuscular mycorrhiza and soil nitrogen cycling. Soil Biol. Biochem. 46, 53-62.

Vosátka, M., Albrechtová, J., Patten, R. 2008. The international marked development for mycorrhizal technology. In: A. Varma (ed). Mycorrhiza: State of the Art, Genetics and Molecular Biology,
Eco-Function, Biotechnology, Eco-Physiology, Structure and Systematics. $3^{\text {rd }}$ Ed. SpringerVerlag, pp: 419-438.

Willems, A. 2007. The taxonomy of rhizobia: an overview In: E. Velázquez, C. RodríguezBarrueco (eds). First International Meeting on Microbial Phosphate Solubilization. Series: Developments in Plant and Soil Sciences. Springer, pp: 3-14.

Willis, A., Rodrigues, B.F., Harris, P.J.C. 2013. The ecology of arbuscular mycorrhizal fungi. Crit. Rev. Plant Sci. 32, 1-20.

Willmann, M., Gerlach, N., Buer, B., Polatajko, A., Nagy, R., Koebke, E., Jansa, J., Flisch, R., Bucher, M. 2013. Mycorrhizal phosphate uptake pathway in maize: vital for growth and cob development on nutrient poor agricultural and greenhouse soils. Frontiers in Plant Sci. 4, 533.

Whitelaw, M.A. 2000. Growth promotion of plants inoculated with phosphate-solubilizing fungi. Advanc. Agron. 69, 99-151.

Xie, X., Huang, W., Liu, F., Tang, N., Liu, Y., Lin, H., Zhao, B. 2013. Functional analysis of the novel mycorrhiza-specific phosphate transporter AsPT1 and PHT1 family from Astragalus sinicus during the arbuscular mycorrhizal symbiosis. New Phytol. 198, 836-852.

Zaidi, A., Khan, M.S. 2007. Stimulatory effects of dual inoculation with phosphate solubilising microorganisms and arbuscular mycorrhizal fungus on chickpea. Austral. J. Experim. Agricul. 47, 1016-1022.

Zancarini, A., Lépinay, C., Burstin, J., Duc, G., Lemanceau, P., Moreau, D., Munier-Jolain, N., Pivato, B., Rigaud, T., Salon, C., Mougel, C. 2013. Combining molecular microbial ecology with ecophysiology and plant genetics for a better understanding of plant-microbial communities' interactions in the rhizosphere. In: 
F.J. de Bruijn (ed). Molecular Microbial Ecology of the Rhizosphere, vol 1. Wiley Blackwell, USA, pp: 69-86.

Zapata, F. 1990. Isotope techniques in soil fertility and plant nutrition studies. In: G. Hardarson (ed). Use of Nuclear Techniques in Studies of SoilPlant Relationships. IAEA, Vienna, pp: 61-128.

Zapata, F., Axmann, H. 1995. $\mathrm{P}^{32}$ isotopic techniques for evaluating the agronomic effectiveness of rock phosphate materials. Fertilizer Research 41, 189-195.

Zapata, F., Roy, R., 2004. Use of phosphate rocks for sutainable agriculture. Food and Agriculture Organization of the United Nations and International Atomic Energy Agency, Rome, 148 p.
Zhang, L., Fan, J., Ding, X., He, X., Zhang, F., Feng, G. 2014. Hyphosphere interactions between an arbuscular mycorrhizal fungus and a phosphate solubilizing bacterium promote phytate mineralization in soil. Soil Biol. Biochem. 74, 177-183.

Zolla, G., Bakker, M.G., Badri, D.V., Chaparro, J.M., Sheflin, A.M., Manter, D.K., Vivanco, J. 2013. Understanding root-microbiome interactions. In: F.J. de Bruijn (ed). Molecular Microbial Ecology of the Rhizosphere, vol 2. Wiley Blackwell, pp: 745-754. i> 